United States Department of the Interior

Geological Survey

\title{
ANALYSIS OF THERMAL DATA FROM DRILL HOLES UE25a-3 AND UE25a-1, CALICO HILLS AND YUCCA MOUNTAIN, NEVADA TEST SITE
}

by

J. H. Sass, Arthur H. Lachenbruch, and C. W. Mase

U.S. Geological Survey Open-File Report $80-826$

1980

This report is preliminary and has not been edited or reviewed for conformity with Geological Survey standards and nomenclature. 


\begin{abstract}
Thermal data from two sites about $20 \mathrm{~km}$ apart in the Nevada Test Site indicate that heat flow both within and below the upper 800 meters is affected significantly by hydrothermal convection. For hole UE25a-1, Yucca Mountain, the apparent heat flow above the water table $(\sim 470 \mathrm{~m})$ is $54 \mathrm{mWm}^{-2}$ $(\sim 1.3 \mathrm{HFU})$. Below the water table, the temperature profile indicates both upward and downward water movement within the hole and possibly within the formation. Hole UE25a-3, Calico Mountain, is characterized by conductive heat flux averaging $135 \mathrm{mWm}^{-2}$ ( $\left.\sim 3.2 \mathrm{HFU}\right)$ to a depth of about 700 meters below which water appears to be moving downward at the rate of nearly 1 ft $\mathrm{y}^{-1}\left(255 \mathrm{~mm} \mathrm{y}^{-1}\right)$. Between 735 and 750 meters, the hole intersected a nearly vertical fault along which water seems to be moving vertically downward. The nearly threefold variation in conductive heat flow over a lateral distance of only $20 \mathrm{~km}$ suggests the presence of a more deeply seated hydrothermal convective system with a net upward flow beneath Calico Hills and a net downward flow beneath Yucca Mountain.
\end{abstract}




\section{INTRODUCTION}

The holes (Figure 1) were drilled during the summer and early autumn of 1978. Details of the drilling program, surface and subsurface geology and geophysical logs are given by Maldonado and others (1979) and by Spengler and others (1979). Temperature logs were obtained by Thomas H. Moses, Jr. of the U.S. Geological Survey in April 1979, by which time all temperature disturbances introduced by the drilling process should have subsided. Temperature profiles below the water table (Figure 2) imply very different thermal and hydrologic regimes within the two holes. UE25a-1 (hereafter referred to as hole 1) shows striking curvature above $680 \mathrm{~m}$ that can only be related to upward water movement either in the hole or in the formation. Below $680 \mathrm{~m}$ there is minor curvature, but much smaller than that found above. The bottom part of UE25a-3 (hole 3) also shows some curvature albeit not as conspicuous as that for hole 1 . Since both holes are obviously not conductive and show the effects of vertical water movement, we shall analyze the data from both a conductive and convective point of view.

The following symbols and units are used in the remainder of this report:

$\mathrm{T}$, temperature, ${ }^{\circ} \mathrm{C}$

$\mathrm{K}$, thermal conductivity, $\mathrm{W} \mathrm{m}^{-1} \mathrm{~K}^{-1}$ or mcal cm $\mathrm{cm}^{-1} \mathrm{~s}^{-10} \mathrm{C}^{-1}$

$z$, depth, m positive downwards

$\nabla_{z}$, vertical (seepage) velocity $\mathrm{m} \mathrm{s}^{-1}$ or $\mathrm{mm} \mathrm{y}^{-1}$ or volume flux of water

$\Gamma$, vertical temperature gradient, ${ }^{\circ} \mathrm{K} \mathrm{km}^{-1}$ or ${ }^{\circ} \mathrm{C} \mathrm{km}^{-1}$

$\mathrm{q}$, vertical conductive heat flow, $\mathrm{mWm}^{-2}$ or $\mathrm{kW} \mathrm{km}^{-2}$, or $\mathrm{HFU}\left(10^{-6} \mathrm{cal} \mathrm{cm}^{-2} \mathrm{~s}^{-1}\right): 1 \mathrm{HFU}=41.86 \mathrm{mWm}^{-2}$ 


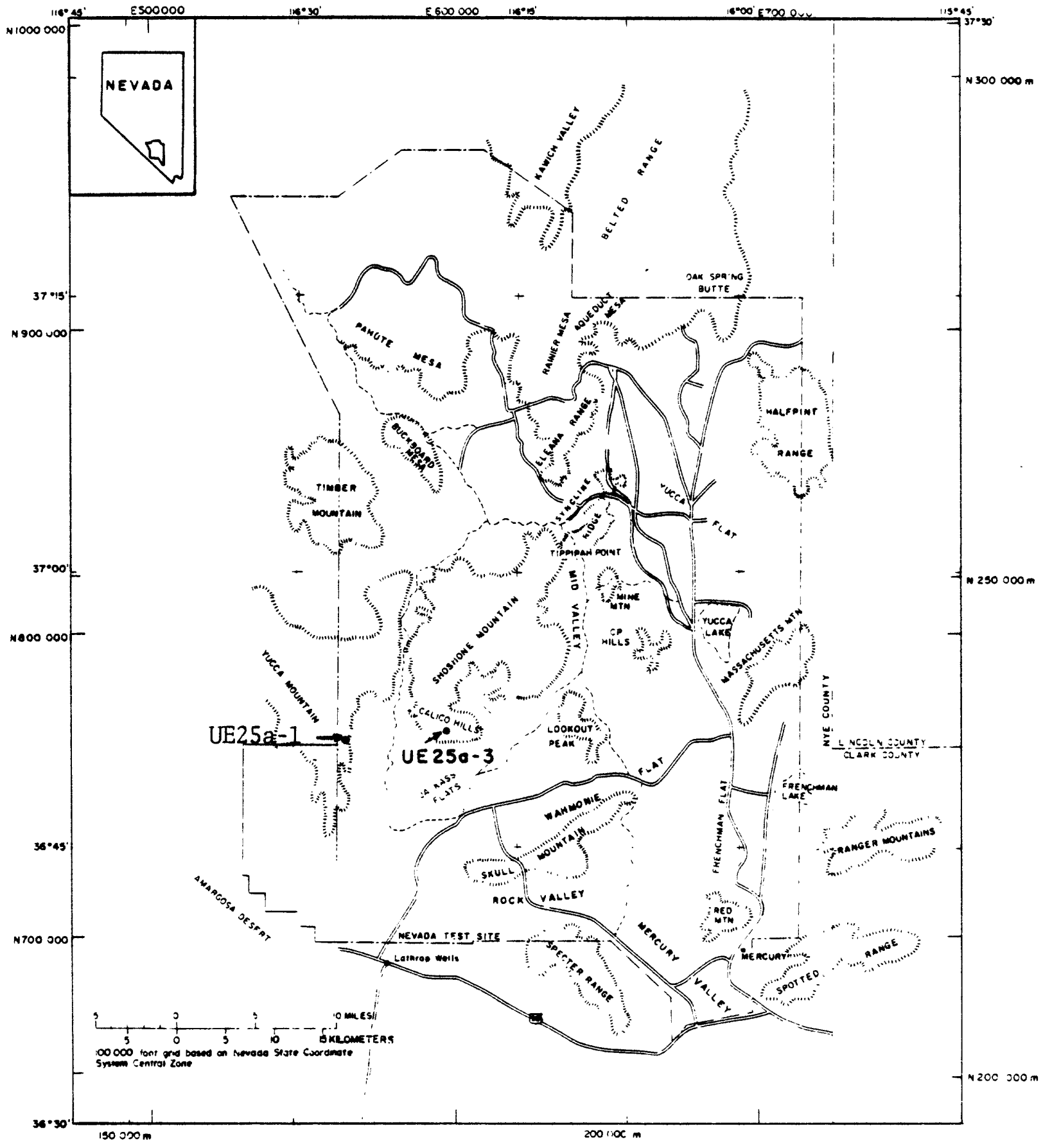

Figure 1. Location of UE25a-3 and UE25a-1 drill holes. 


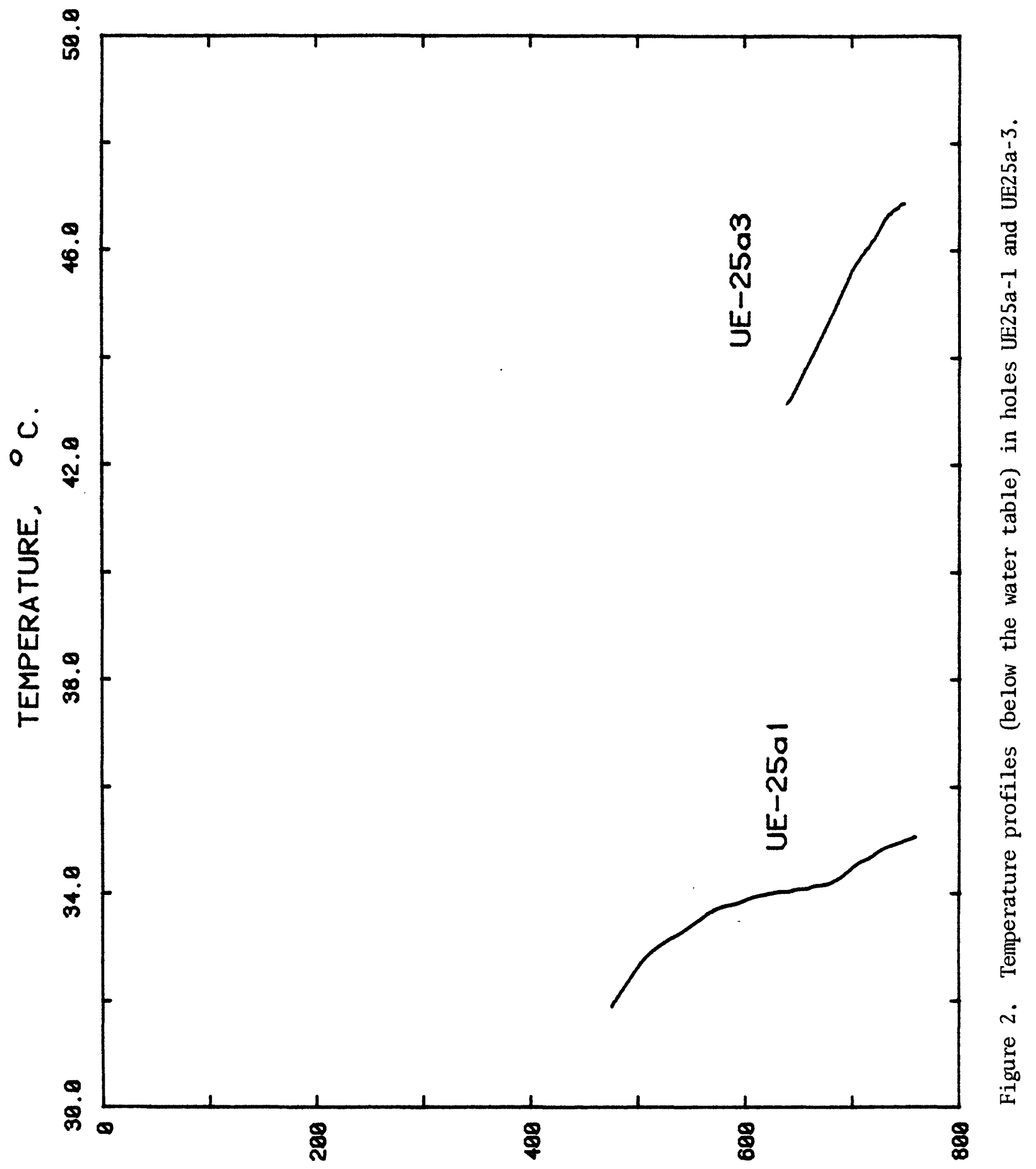

s dozow 'HLd $\exists O$ 
Acknowledgments: We thank Manuel Nathenson and Howard Oliver for their reviews of the original manuscript.

\section{THERMAL CONDUCTIVITY}

Hole 1 was so obviously disturbed by water flow that we did not measure any thermal conductivities. The hole penetrated Miocene tuffs and tuffaceous sediments for its entire length (Spengler and others, 1979). From measurements made on these rocks at other locations on the Test Site, we can assume a representative value of $1.5 \mathrm{~W} \mathrm{~m}^{-1} \mathrm{~K}^{-1}$ (Sass and Munroe, 1974) as being appropriate for our thermal calculations.

Hole 3 penetrated the argillites and altered argillites of Unit $J$ of the Devonian and Mississippian Eleana formation to a depth of about $720 \mathrm{~m}$. The lowermost 50 meters penetrated marble and marbleized carbonate rocks thought to be Unit I of the Eleana formation (Maldonado and others, 1979). Thermal conductivities were measured on saturated core mainly using the needle-probe system described by Lachenbruch and Marshall (1966). The range of conductivities for the argillites and altered argillites of the lower sub-unit of Unit $J$ (Table 1) is comparable to that found in the Syncline Ridge area to the northeast (Figure 1, see also Figure 4 of Sass and others (1980b)) with the low conductivities around $733 \mathrm{~m}$ representing the mudstone inclusions described in Table 1 of Maldonado and others (1979). The harmonic mean thermal conductivity of the carbonate section $\left(2.47 \pm 0.35 \mathrm{~W} \mathrm{~m}^{-1} \mathrm{~K}^{-1}\right)$ is somewhat lower than that for the Argillite $(3.10 \pm 0.56)$, this despite the fact that the gradient within the carbonate section also is lower. 
TABLE 1. Thermal Conductivities from Hole 非UE25a-3

\begin{tabular}{|c|c|c|c|c|}
\hline \multicolumn{2}{|c|}{ Depth } & \multicolumn{2}{|c|}{ Thermal conductivity } & \multirow[t]{2}{*}{ Formation } \\
\hline $\mathrm{ft}$ & $\mathbf{m}$ & mcal $\mathrm{cm}^{-1} \mathrm{~s}^{-10} \mathrm{C}^{-1}$ & $W m^{-1} K^{-1}$ & \\
\hline $\begin{array}{l}2009 \\
2076 \\
2076.2 \\
2124.6 \\
2124.8 \\
2149.7 \\
2241.0 \\
2342\end{array}$ & $\begin{array}{l}612.35 \\
632.77 \\
632.83 \\
647.58 \\
647.64 \\
655.23 \\
683.06 \\
713.85\end{array}$ & $\begin{array}{r}8.59 \\
10.63 \\
8.73 \\
8.36 \\
7.40 \\
3.34 \\
8.31 \\
13.02\end{array}$ & $\begin{array}{l}3.59 \\
4.45 \\
3.65 \\
3.50 \\
3.10 \\
1.40 \\
3.48 \\
5.45\end{array}$ & $\begin{array}{l}\text { Eleana Unit J } \\
\text { (Argillite) }\end{array}$ \\
\hline $\begin{array}{l}2371.4 \\
2371.5 \\
2379.9 \\
2380.1 \\
2406.1 \\
2406.4 \\
2465.3 \\
2465.4 \\
2523.2 \\
2523.3\end{array}$ & $\begin{array}{l}722.81 \\
722.84 \\
725.40 \\
725.46 \\
733.38 \\
733.46 \\
751.43 \\
751.46 \\
769.08 \\
769.11\end{array}$ & $\begin{array}{r}6.82 \\
6.98 \\
6.42 \\
6.12 \\
3.29 \\
3.28 \\
10.39 \\
8.90 \\
9.50 \\
6.30\end{array}$ & $\begin{array}{l}2.85 \\
2.92 \\
2.69 \\
2.56 \\
1.38 \\
1.37 \\
4.35 \\
3.72 \\
3.97 \\
2.63\end{array}$ & $\begin{array}{c}\text { Eleana Unit I(?) } \\
\text { (Marble) }\end{array}$ \\
\hline
\end{tabular}




\section{ANALYSIS OF DATA}

The data analysis is summarized in Table 2. For linear segments of the temperature profiles, conductive heat flows were calculated simply by multiplying the gradient over that segment $(\Gamma)$ by the thermal conductivity (K). The conductivity used was either the harmonic mean of the measured conductivities within that segment or an estimate based on measurements of the same formation elsewhere. There is a reasonably good correlation between extrapolated ground surface temperature and collar elevation within the Nevada Test Site (Sass and others, report in preparation, 1980). From this relation, we estimated mean annual ground-surface temperatures of $14.8^{\circ} \mathrm{C}$ and $13.9^{\circ} \mathrm{C}$ for holes 1 and 3 , respectively. (The value for hole 3 was consistent with temperatures measured in air at depths of about $180 \mathrm{~m}$ ). From the latter temperatures and the temperatures measured near the static water level, we were able to estimate gradients and hence heat flows for the upper parts of the holes. Inasmuch as we used estimated conductivities based on measurements on (apparently) saturated samples, these heat-flow values probably will be overestimates with an uncertainty that will vary with such factors as degree of in situ saturation and porosity.

For systematically non-linear segments displaying curvature in the temperature-depth profile, a one-dimensional diffused upward (or downward) flow model similar to that described by Lachenbruch and Sass (1977, equations 10 and 11) and Bredehoeft and Papadopulous (1965) was used to calculate seepage velocity (positive downwards). In this model we have assumed diffused vertical flow within the formation and borehole; however, an inherent ambiguity exists in this assumption since the lack of casing and cement causes convection within the formation to be indistinguishable from fluid flow within the borehole. Although for our interpretation, we have 


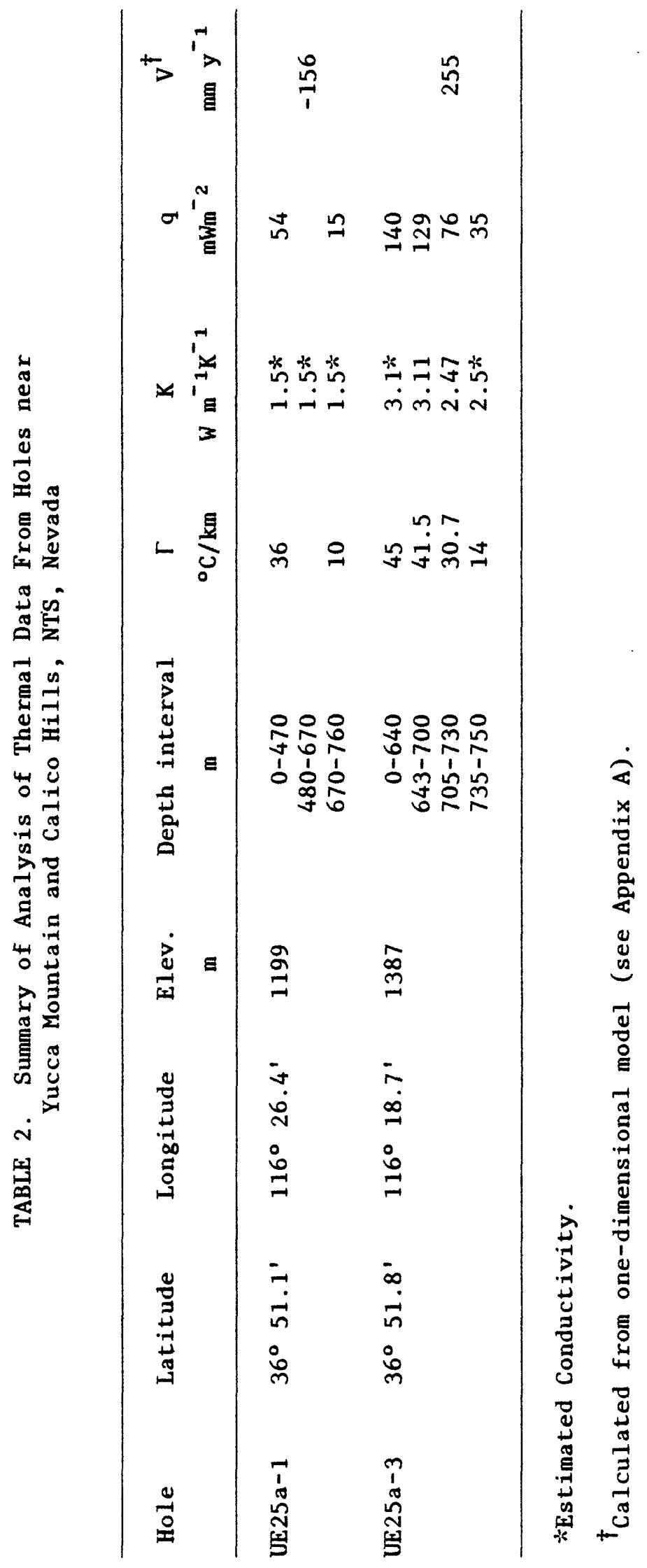


assumed simple one-dimensional diffused vertical flow, due in part to the lack of sufficient heat-flow data in the area, other more complex groundwater flow patterns (two and three dimensional) can be envisioned to explain the temperature data.

UE25a-1. For hole 1, we estimated a heat flow of $54 \mathrm{mWm}^{-2}(\sim 1.3 \mathrm{HFU})$ for the upper 470 meters (Table 2). The upper part of the temperature profile below the water table (480-670 m, Figures 2 and 3) shows strong, consistent downard curvature. This curvature can only be attributed to either upward water movement within the borehole or convection within the formation; therefore, making any estimates of conductive heat flow across this section meaningless. The flow model (Appendix A) provided a reasonably good fit between 480 and 670 meters and resulted in an estimated upward flow with a seepage velocity of $156 \mathrm{~mm} \mathrm{y}^{-1}$ (Figure 3 and Table 2). This zone corresponds approximately to a densely fractured, bedded, non- to partially welded tuff. Below 670 meters, fracture density decreases markedly and the hole penetrates a section of moderately welded tuff beginning at about $710 \mathrm{~m}$ (Spengler and others, 1979). This lower segment of the profile is undulant (Figure 3), suggesting zones of both upward and downward water movement, but at much lower vertical velocities than in the zone above. The overall gradient in this zone is about $10^{\circ} \mathrm{C} / \mathrm{km}$ leading to a conductive heat-flow estimate of $15 \mathrm{mWm}^{-2}$ ( $\left.0.4 \mathrm{HFU}\right)$. The low heat flow probably is caused by lateral water movement with a downward velocity component either within or below this section.

UE25a-3. Temperatures measured in air at about $180 \mathrm{~m}$ are consistent with a ground-surface temperature of $13.9^{\circ} \mathrm{C}$. From this, we estimate a gradient of $45^{\circ} \mathrm{C} \mathrm{km}^{-1}$ and a heat flow of $140 \mathrm{mWm}^{-2}$ (3.3 HFU). Considering the uncertainties, this value agrees well with the heat flow of $129 \mathrm{mWm}^{-2}$ 


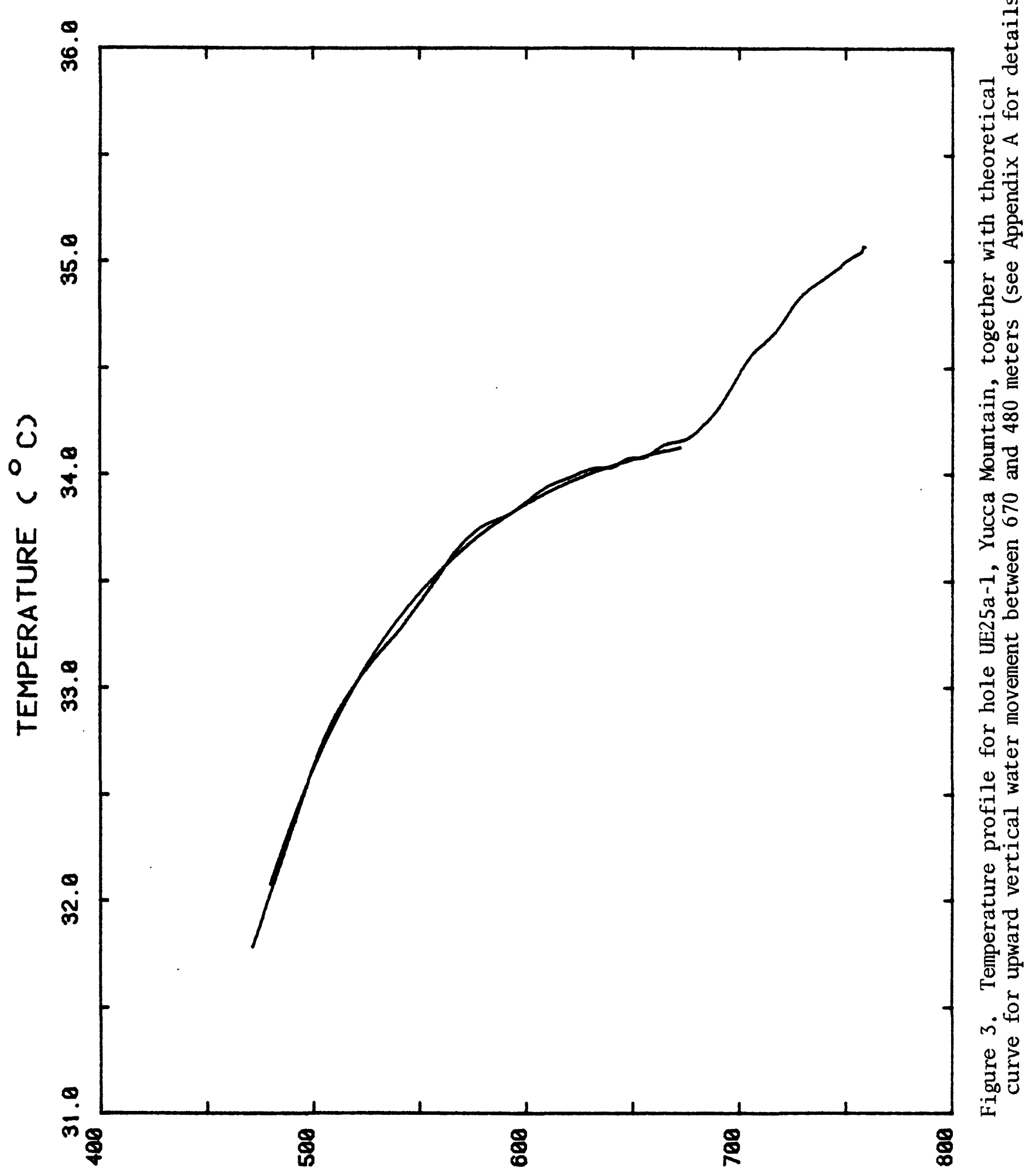

(w) HLd $\exists O$ 
determined for the linear segment of the temperature profile between 643 and $705 \mathrm{~m}$ in the altered argillite, lower sub-unit, unit $\mathrm{J}$ of the Eleana formation (Maldonado and others, 1979). Below $705 \mathrm{~m}$ the hole enters a carbonate zone of lower conductivity; however, the gradient drops and curvature is evident in the temperature profile (Figures 2 and 4) strongly suggesting downward water movement. Between 705 and $730 \mathrm{~m}$ (Figure 4, Table 2), the curvature was sufficiently gentle that we were able to make a formal calculation of conductive heat flux as well as making a velocity estimation from the onedimensional flow model which resulted in a downward flow of $255 \mathrm{~mm}^{-1}$. Between 735 and 750 meters (Figure 4, Table 2), the temperature profile is quite shaky and the gradient becomes very low $\left(\sim 14^{\circ} \mathrm{C} / \mathrm{km}\right)$. This might be caused by downward water flow along a steeply dipping $\left(\sim 85^{\circ}\right)$ fault that crosses the hole at $746 \mathrm{~m}$ (Maldonado and others, 1979). A formal calculation of heat flow in this section yields a value of about $35 \mathrm{mWm}^{-2}$ ( $\sim .8 \mathrm{HFU}$ ). 


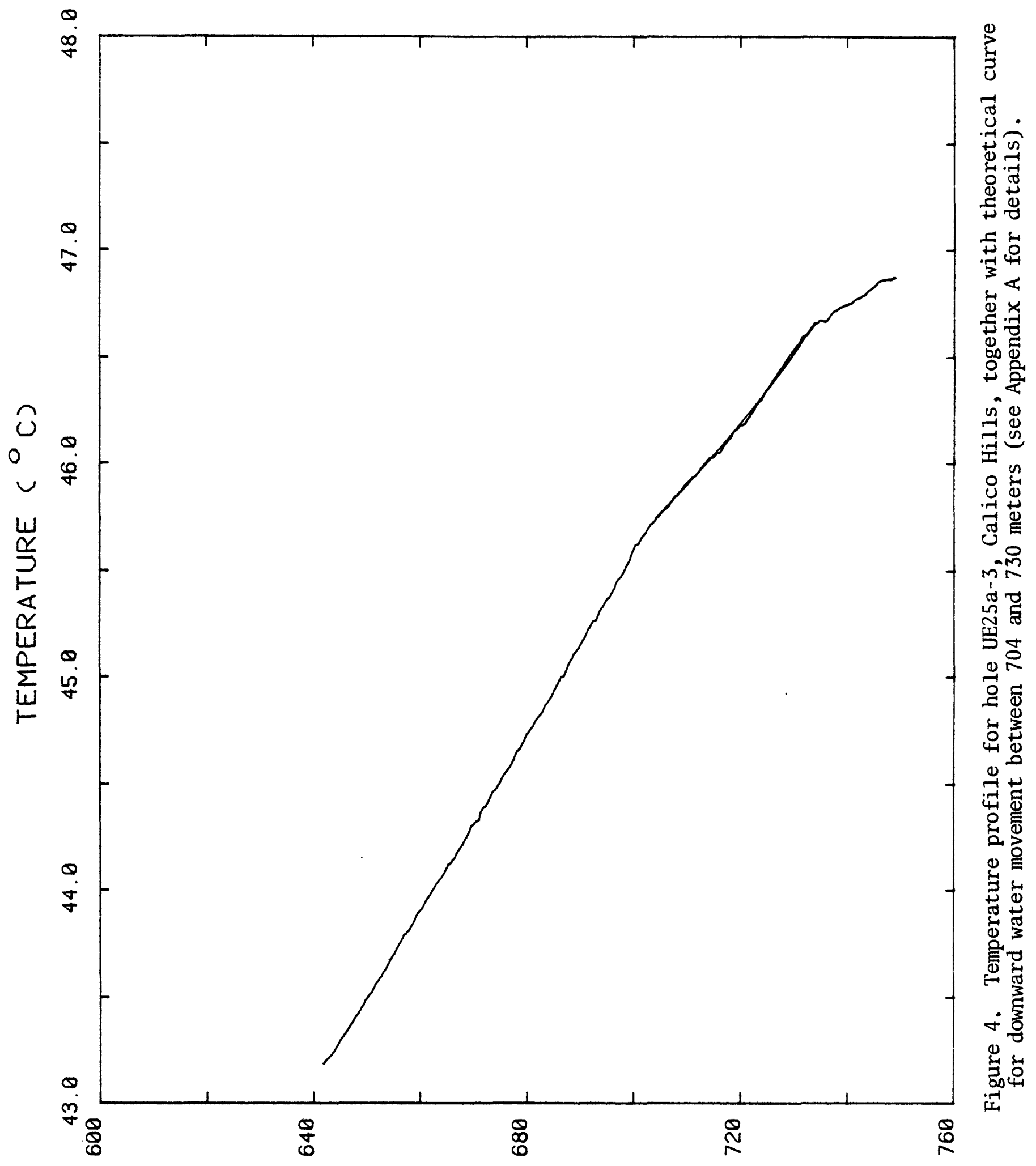

(w) $H \perp d \exists O$ 


\section{DISCUSSION}

Measurements in two holes only $20 \mathrm{~km}$ apart indicate substantially different thermal regimes beneath the two locations. Lateral variations like this in the hydrothermal regime are characteristic of the Nevada Test Site (Sass and others, report in preparation, 1980). In hole 1 , the average heat flow above the water table is at least $30 \mathrm{mWm}^{-2}$ less than the characteristic Basin and Range average $\left(80-100 \mathrm{mWm}^{-2}\right)$. In hole 3 , it is considerably above that average. The temperature profile below the water table in hole 1 is dominated by the effects of moving water. In hole 3 there is a $600 \mathrm{~m}$ section in which heat flow is primarily by conduction. Below this section convection of water plays a significant role. Two observations can be made concerning the section of hole 3 between 705 and $730 \mathrm{~m}$ (Figure 4 and Table 2). First, when we compare this section with the strongly convecting section of hole 1 (Figure 2) it seems intuitively that a relatively trivial amount of water flow is involved; however, owing to a higher conductive gradient, a higher conductivity and the smaller thickness of the zone, our one-dimensional flow model yields a higher velocity for the convection in hole 3 than for the more conspicuously disturbed section of hole 1 . Secondly the rather smooth variation in gradient over this section gives us an opportunity to test our assumption of one-dimensional flow.

The magnitude of the true heat flow across this section may be estimated from the equation

$$
q_{T}=q_{s} e^{N_{P}}
$$

(see equation 12, Appendix A) where $\mathrm{q}_{\mathrm{T}}$ is the heat flow across the section 
in the absence of convection, $q_{s}$ is the surface heat flow out of the section in the presence of convection and $\mathrm{N}_{P}$ is the Peclet number, the ratio of convective diffusivity to thermal diffusivity. From the parameters of our model, the interpretation of the temperature depth curve would imply a vertical velocity of $255 \mathrm{~mm} \mathrm{yr}^{-1}$ (Table 2) or $8.09 \times 10^{-9} \mathrm{~m} \mathrm{sec}^{-1}$, a Peclet number of .38 , and a surface heat flow of $61 \mathrm{mWm}^{-2}$. This amounts to a true heat flow of $91 \mathrm{mWm}^{-2}$ across the section as compared with $129 \mathrm{mWm}^{-2}$ in the zone above (Table 2). Considering the uncertainties, this is reasonable agreement.

Figure 5 places the present study area within the context of the southern Great Basin; in particular, we can see its relation to the "Eureka Low," defined by Sass and others (1971) on the basis of a rather sharp transition controlled by fewer than two dozen data points and outlined in Figure 5 by the $1.5 \mathrm{HFU}\left(\sim 60 \mathrm{mWm}^{-2}\right)$ contour. Both holes are located outside but near the southern boundary of the Eureka Low in an area generally characterized by "normal" Basin and Range heat flow (Figure 5). In this context both sites have conspicuously anomalous heat flows, as we noted at the beginning of this discussion. It should be further noted, however, that many temperature profiles of the same approximate quality were rejected from the original analysis of Sass and others (1971) precisely because of the lack of internal consistency and the obvious hydrologic features we are discussing here. Thus, we are dealing with two distinctly different types of data which serve quite different purposes. The data originally selected are probably a valid indicator of regional heat flow, at least to depths of $1 \mathrm{~km}$ or so. Data like those discussed in this report may or may not have regional significance; it is certain, however, that they do contain information on local hydrology . 


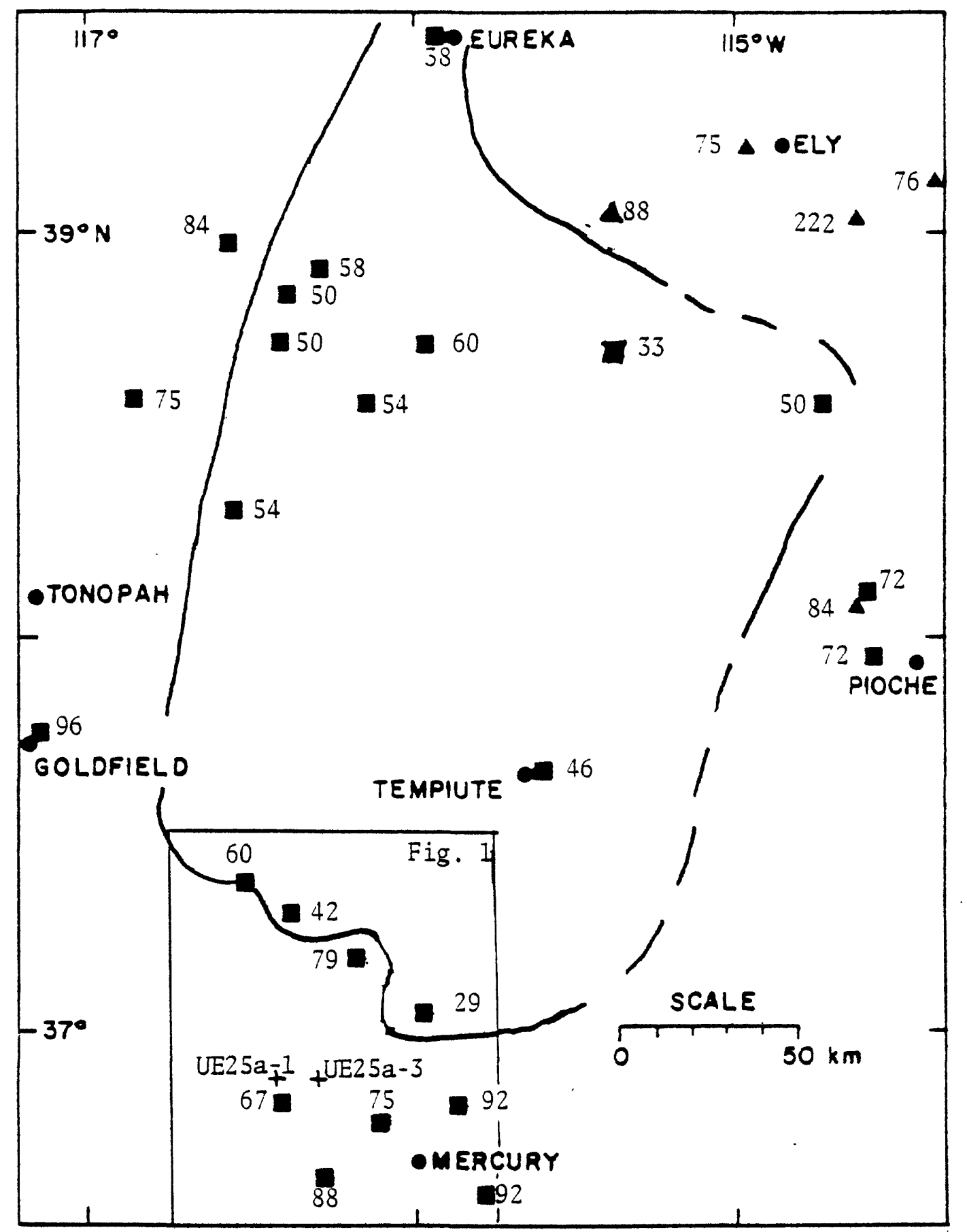

Figure 5. Map of south-central Nevada showing the extent of the "Eureka Low." Bux outlines area of Figure 1. New sites indicated by crosses. Heat flow in $\mathrm{mim}^{-2}$. 
There is no question that hole 1 describes merely a local situation. Hole 3 does, however, yield internally consistent heat-flow data down as far as the carbonates of Unit I. Had the hole been terminated short of this depth, we would have accepted the heat-flow value as a "Class 1 " determination (Sass and others, 1971), and we would have been faced with explaining a heat flow more characteristic of the "Battle Mountain high" than of this region as interpreted by Sass and others (1971) (see also Lachenbruch and Sass, 1977; Sass and others 1980a). This nearly three-fold variation in conductive heat flow between holes 1 and 3 and the lower temperatures observed in hole 1, over a lateral distance of $20 \mathrm{~km}$, suggests the presence of a more deeply seated hydrothermal convective system with a net upward flow beneath Calico Hills and a net downward flow beneath Yucca Mountain. Viewed from an even broader perspective, the high heat-flow value for hole 3 provides support for yet another interpretation of the heat-flow field in southern Nevada. Figure 6 shows the latest version of the heat-flow contour map of the western United States (Sass and others, 1980a). Superimposed on this (heavy line, Figure 6) is the $2.5 \mathrm{HFU}\left(\sim 100 \mathrm{mWm}^{-2}\right)$ contour as determined by Swanberg and Morgan (1978, 1980a) from an empirical relation (calculated over $1^{\circ}$ squares) between heat flow and silica geotemperatures. It is interesting that this interpretation places much of the Great Basin including most of the Eureka Low and all of the Nevada Test Site within the same heat-flow province as that defined from conventional measurements by the eastern Snake River Plain and the Battle Mountain high. Clearly, a reinterpretation (presently in progress) of earlier thermal data of lower quality and additional high-quality heat-flow measurements are required to resolve the paradox implied by the two contrasting interpretations of Figure 6. 


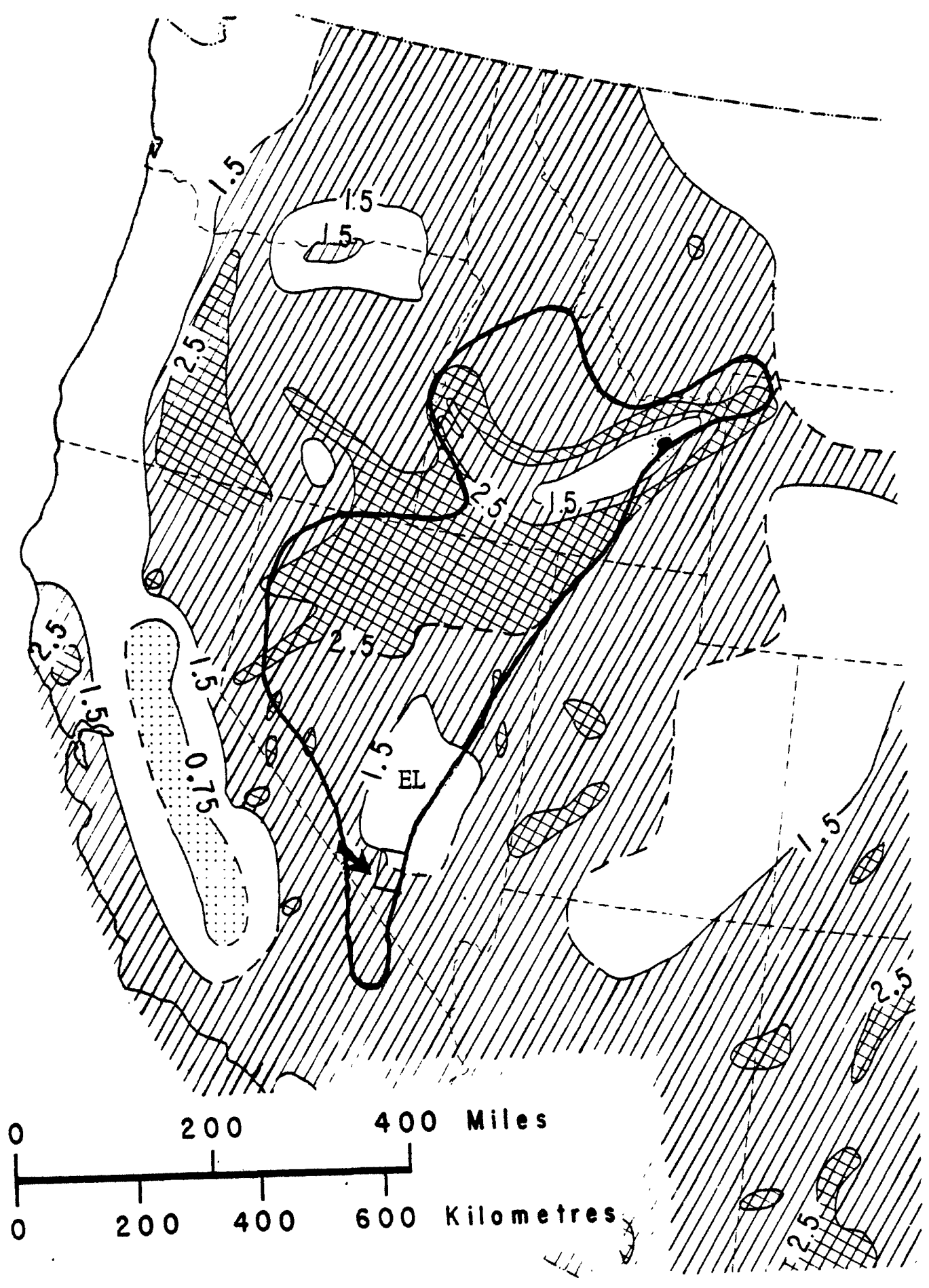

Figure 6. Map of Western United States showing heat-flow contours (in HFU). EL is Eureka Low. Arrow indicates outline of approximate boundaries of the Nevada Test Site (NTS). Heavy line is $2.5 \mathrm{HFU}$ contour, based on the relation between silica temperatures and heat flow (Swanberg and Morgan, 1978). 


\section{APPENDIX A}

Solution of the One-dimensional Heat Transfer Equation

The steady state or time independent conductive and convective heat transfer equation is given by

$$
\nabla \cdot \mathrm{KVT}-\nabla \cdot \rho_{\mathrm{f}} \mathrm{C}_{\mathrm{f}} \overrightarrow{\mathrm{VT}}=0
$$

In this equation $\rho_{f}$ and $C_{f}$ are the density and specific heat of the fluid phase, $\mathrm{K}$ is the thermal conductivity of the solid-fluid composite, $\vec{V}$ is the volume averaged velocity field and $\mathrm{T}$ is temperature. For uniform conductivity, $\mathrm{K}$, and steady ground water flow in which the divergence of the velocity field, $\nabla \cdot \vec{V}$, and viscous dissipation are negligible equation (1) reduces to

$$
K \nabla^{2} T-\rho_{f} C_{f} \vec{V} \cdot \nabla T=0
$$

The above equation is strictly valid only if the solid and fluid phases can be regarded as coexisting continua. This restriction is satisfied if the pore spaces and fractures through which the flow takes place are much smaller than the distance over which there is a resolvable temperature change (Kilty and others, 1978).

A dimensionless form of the energy equation is useful for qualitatively discussing the behavior of conductive and convective heat transfer. If we consider the quantites, $L_{0}, V_{0}$ and $T_{0}$ to be respectively characteristic length, velocity and temperature in the convective flow, then we can rewrite the heat-transfer equation with the transformations (Kilty and others, 1978)

$$
\begin{aligned}
& \nabla^{*}=\mathrm{L}_{0} \nabla \\
& \mathrm{V}^{*}=\overrightarrow{\mathrm{V}} / \mathrm{V}_{0}
\end{aligned}
$$




$$
\theta=\left(\mathrm{T}-\mathrm{T}_{\mathrm{s}}\right) /\left(\mathrm{T}_{0}-\mathrm{T}_{\mathrm{s}}\right)
$$

which results in a dimensionless energy equation

$$
\frac{1}{\mathrm{~N}_{\mathrm{P}}} \nabla * 2 \theta-V * \cdot \nabla * \theta=0
$$

where $N_{P}$ is the Peclet number defined as

$$
N_{P}=\frac{\rho_{f} C_{f} V_{o} L_{o}}{K}
$$

The Peclet number is the ratio of convective diffusivity $\left(V_{0} L_{0}\right)$ to thermal diffusivity $\left(\mathrm{K} / \rho_{\mathrm{f}} \mathrm{C}_{\mathrm{f}}\right)$. If the Peclet number is small, the second term of equation (6) (convection) is negligible and conduction dominates the heat transfer. In this case the solution is very similar to that of pure conduction. If the Peclet number is large, the first term of equation (6) (conduction) is negligible and convection is dominating the heat transfer. In this case, equation (6) reduces to

$$
\nabla \div \theta \div \theta=0
$$

The only realistic solution of this equation is $\theta$ equal to a constant throughout the most rapid parts of the fluid flow. Therefore, the Peclet number may also be considered as a ratio of heat transferred by convection to the heat transferred by conduction (Rosenberger, 1978; Kilty and others, 1978, similar to s of equation (11a), Lachenbruch and Sass, 1977).

The above qualitative discussion of the heat-transfer equation demonstrates the character of conductive and convective heat transfer, the analysis of a real system requires a solution to heat transfer equation for a 
specific flow field. For this report, we have considered vertical onedimensional steady convection and equation (1) reduces to

$$
\frac{\partial^{2} T}{\partial^{2} z}-\frac{\rho_{f} C_{f}}{K} v_{z} \frac{\partial T}{\partial z}=0
$$

or equation (9) of Lachenbruch and Sass (1977)

$$
\frac{\partial q}{\partial z}-\frac{\rho_{f} C_{f}}{K} v_{z} q=0
$$

In these equations $V_{z}$ is the volume averaged velocity and $q$ is the vertical conductive heat flow. The solution to equation (10) is determined by specifying at least one of the boundary temperatures and one of the boundary heat flows. A useful consistent solution is given by (modified from equation (10) of Lachenbruch and Sass, 1977)

$$
q(z)=q_{s} e^{\left(\frac{N_{p}}{L_{o}}\right) z}
$$

where $q_{s}$ is the surface heat flow out of the layer. The corresponding temperature field is given by

$$
T(z)=\frac{q_{s}}{\rho_{f} C_{f} V_{z}} \cdot\left(e^{\left(\frac{N_{p}}{L_{o}}\right) z}-1\right)+T_{s}
$$

where $T_{S}$ is the mean surface temperature of the layer. For this model, the water flows vertically downward through the layer until reaching the lower boundary upon which it flows horizontally with no change in temperature, providing a source (or sink) for the vertical mass flow to (or from) the surface.

Tables A-1 and A-2 lists the details of the one-dimensional model for boreholes UE25a-3 and UE25a-1. The parameters for the models were computed via the temperature data and the method of least squares utilizing equations (11) and (12). 


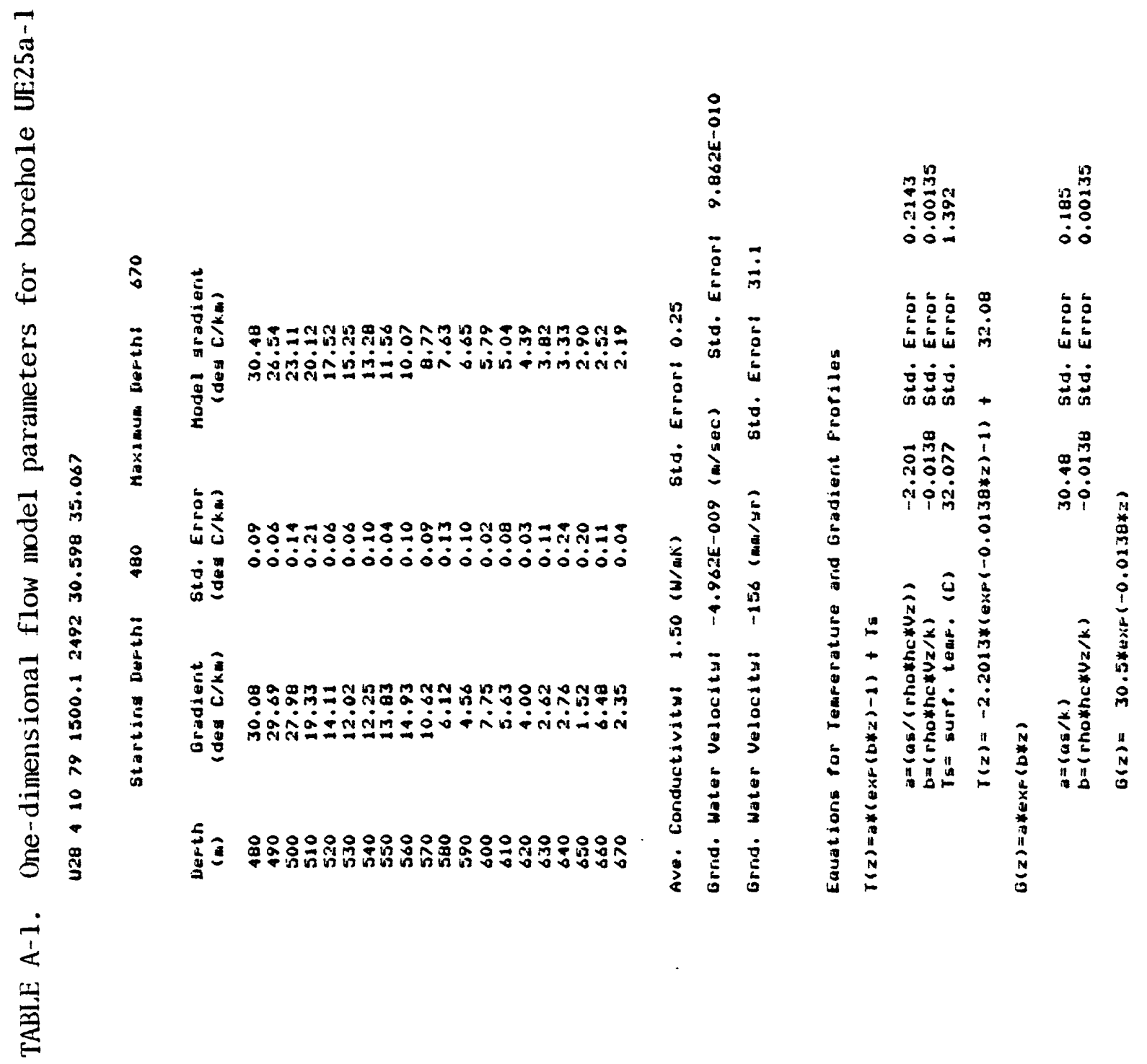




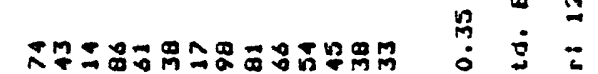

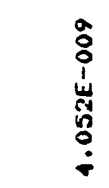

흔

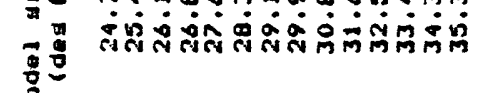

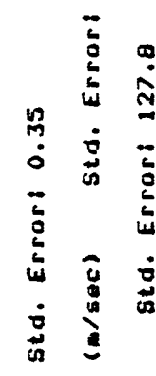

范

$\stackrel{0}{8}$

造

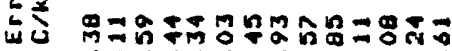

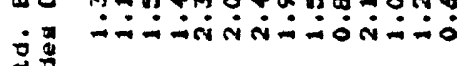

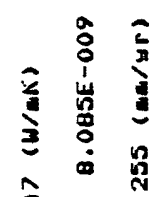

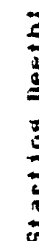

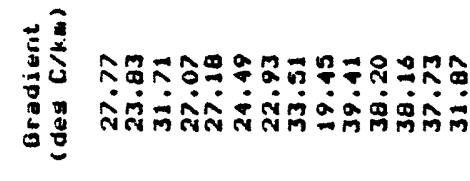

iे

i

量

용

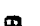

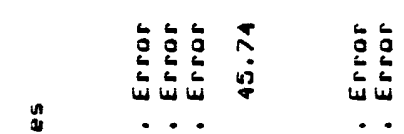

$\frac{a}{3}$

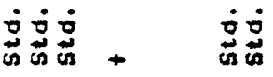

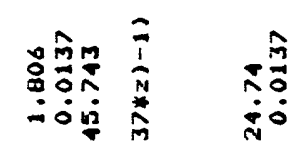

iें

in

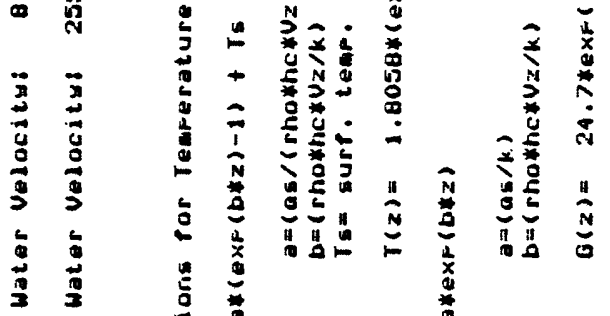

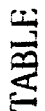

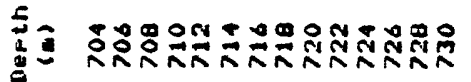

¿

要 


\section{References}

Bredehoeft, J. D., and Papadopulos, I. S., 1965, Rates of vertical groundwater movement estimated from the earth's thermal profile: Water Resources Research, v. 1, p. 325-328.

Kilty, K. T., Chapman, D. S., and Mase, C. W., 1978, Aspects of forced convective heat transfer in geothermal systems: Department of Energy, Division of Geothermal Energy, Contract No. EG-78-C-07-1701, University of Utah.

Lachenbruch, A. H., and Marshall, B. V., 1969, Heat flow in the Arctic: Arctic, v. 22, p. 300-311.

Lachenbruch, A. H., and Sass, J. H., 1977, Heat flow in the United States and the thermal regime of the crust, in Heacock, J. G., ed., The Earth's Crust--Its Nature and Physical Properties: American Geophysical Union Geophysical Monograph 20, p. 626-675.

Maldonado, F., Muller, D. C., and Morrison, J. N., 1979, Preliminary geologic and geophysical data of the UE25a-3 exploratory drill hole, Nevada Test Site Nevada: USGS-1543-6.

Rosenberger, F. E., 1978, Fundamentals of Crystal Growth, vol. 1, Macroscopic Equilibrium and Transport Concepts: Springer-Verlag Publications, Berlin.

Sass, J. H., Blackwell, D. D., Chapman, D. S., Costain, J. K., Decker, E. R., Lawver, L. A., and Swanberg, C. A., 1980a, Heat flow from the crust of the United States, in Touloukian, Y. S., Judd, W. R., and Roy, R. F., eds., Physical Properties of Rocks and Minerals: McGraw-Hill Book Company, in press. 
Sass, J. H., Lachenbruch, A. H., Munroe, R. J., Greene, G. W., and Moses, T. H., Jr., 1971, Heat flow in the western United States: Journal of Geophysical Research, v. 76, p. 6376-6413.

Sass, J. H., Lachenbruch, A. H., Munroe, R. J., and Moses, T. H., Jr., 1980b, Thermal data from the Syncline Ridge area, Nevada Test Site: U.S. Geological Survey Open-File Report, in preparation.

Sass, J. H., and Munroe, R. J., 1974, Basic heat-flow data from the United States: U.S. Geological Survey Open-File Report 74-9.

Spengler, R. W., Muller, D. C., and Livermore, R. B., 1979, Preliminary report on the geology and geophysics on drill hole UE25a-1, Yucca Mountain, Nevada Test Site: U.S. Geological Survey Open-File Report 79-1244, 43 p.

Swanberg, C. A., and Morgan, P., 1978, The linear relation between temperatures based on the silica content of groundwater and regional heat flow: A new heat flow map of the United States: Pure and Applied Geophysics, v. 117, p. 227-241.

Swanberg, C. A., and Morgan, P., 1980, The silica heat flow interpretation techniques: Assumptions and applications: Journal of Geophysical Research, in press. 